\title{
Smoking and the Young
}

\author{
A report of a working party of the Royal College of Physicians
}

On 30 June 1992 the Royal College of Physicians of London released its fifth report on smoking and health, entitled Smoking and the Young. The report is 130 pages long. The foreword, preface, major findings, and recommendations are reproduced below by permission of the college. The full report is available from the Royal College of Physicians, 11 St Andrew's Place, Regent's Park, London NW1 4LE, United Kingdom, price $£ 10$ plus $£ 1$ postage and packing $(£ 13$ overseas including postage). For further information contact Stephanie Hall or Alice Grant (tel (44 71) 2459660 or fax (44 71) 823 2066).-ED

\section{Foreword}

The first report on the influences of smoking on health produced by the Royal College of Physicians in 1962 was a turning point in identifying the hazards of tobacco. Specific recommendations were made in subsequent reports which, had they been applied fully, would undoubtedly have already saved the lives of many thousand British smokers. Perhaps more importantly they would have prevented whole cohorts of teenagers in the 1970s and 1980s taking up an expensive and dangerous lifelong habit. This report should spark the new approach required to meet the Government targets on reduction in smoking prevalence. All of us have a responsibility for the health of our children today and in the future. MARGARET TURNER-WARWICK DBE The Royal College of Physicians June 1992

\section{Preface}

This report is the fifth produced by the Royal College of Physicians on the influence of smoking on health. The previous reports, published in $1962,1971,1977$ and $1983^{1-4}$ concentrated on the health effects of active smoking and made specific recommendations to try to reduce levels of tobacco consumption. Over the past 30 years, some progress has been made. For example, individual tobacco consumption has fallen and so have deaths from lung cancer in men. On the other hand, lung cancer has continued to rise in women and the uptake of smoking by teenagers has not changed in the last decade. The figure of 110,000 premature deaths resulting from smoking continues to be cited as the burden which society carries.

This report concerns smoking and the young, since new smokers are enrolled almost entirely from this group. Tobacco smoking is addictive and does far greater harm than any other addictive drug. Thus, once children and young people start to smoke, stopping or 'quitting' becomes extremely difficult and the likelihood is that they will continue to smoke into and throughout adult life. Although previous reports recommended a ban on tobacco advertising and promotion, tobacco advertising continues, aided and abetted by voluntary agreements between the tobacco companies and the UK government. Tobacco companies claim not to promote cigarettes to children, but in order to maintain the number of customers they have to replace the 300 smokers who die every day in the UK as a result of smoking. Most new recruits to smoking are under 18 years of age. Much advertising is now subtle and indirect, centering around sporting events such as motor racing with which youngsters identify. Paradoxically, smoking by sportsmen or women would result in a degree of unfitness incompatible with excellence in their chosen sport.

More recently, information has become available on the hazards of passive smoking in the broadest sense. Unwittingly, non-smoking children and adults are placed at risk from others' smoke, as is the unborn child during pregnancy. A report summarising the present evidence, Passive smoking : a health hazard, has recently been published (1991). ${ }^{5}$

The facts set out above supplied the rationale of the working party who prepared the report to help protect the future health of young people. The report comes at a time of high government awareness of the role of preventive medicine as set out in its consultative document The health of the nation. ${ }^{6}$ Many of the responses to this document identified tobacco as the single most important cause of preventable ill-health in the United Kingdom today. The document states the government's intention to reduce the numbers of people starting to smoke and to increase the numbers who stop smoking. The document establishes targets for a national reduction in smoking prevalence by one-third for men and women by the year 2000. Much of this reduction will have to be by prevention of smoking in the young, although this is best achieved in the context of overall reduction in smoking prevalence at all ages. On current trends, it is difficult to see how these targets are going to be met and a new approach is therefore required. 
The working party who prepared this report included physicians with an interest in the chest and heart (prime systems damaged by smoking), and experts from child health, public health, epidemiology and health promotion.

The report has been divided into several sections. First, the effects of passive smoking on the health of the fetus and children are described. The health effects of active smoking in children, including aspects of nicotine addiction are considered next, followed by a report on the current prevalence and social factors which come into play. Finally, the working party has produced a series of intervention strategies which are based on the premise that children and young people have the right not to be exposed to the adverse health effect of tobacco, either through passive or active smoking. This places responsibility on all of us and the report proposes how this can be achieved at the level of the family, the school, the media, health service, local and central government.

We hope that the recommendations of this report will be implemented in full so that children in the 1990s will avoid taking up and continuing this expensive and dangerous lifelong habit as adults into the 21 st century.

1. Royal College of Physicians. Smoking and health. A report on smoking relation to lung cancer and other diseases. London: Pitman Medical 1962.

2. Royal College of Physicians. Smoking and health now. A new report on smoking and its effects on health. London:

3. Royal College of Physicians. Smoking or health. London: Pitman Medical 1977.

4. Royal College of Physicians. Health or smoking. A follow-up report. London: Pitman Medical 1983.

5. Wald NW, Booth C, Doll R et al (eds). Passive smoking : a health hazard. London: Imperial Cancer Research Fund and Cancer Research Campaign 1991.

6. Department of Health. The health of the nation. A consultative document for health in England. Cm1523. London: HMSO 1991.

Note: References 1-3 are out of print. Reference 4 can be obtained from the Royal College of Physicians.

\section{Major Findings}

Smoking, the fetus and early life

1. Spontaneous abortions (miscarriages) of viable fetuses are increased in pregnant smokers by more than one-quarter.

2. Premature labour is twice as common in pregnant smokers.

3. Babies born to mothers who smoke are lighter by an average 200 grams (approximately half a pound). Paternal smoking also makes babies significantly lighter.

4. Stillbirths and early neonatal deaths (perinatal mortality) are increased by approximately one-third in babies of smokers.

5. The effects of smoking in pregnancy extend well beyond infancy with a reduction in growth and educational achievement.

\section{The effects of passive smoking on the} health of children

6. Children of smoking parents inhale the same amount of nicotine as if they themselves smoked 60-150 cigarettes per year.

7. Over one-quarter of the risk of death due to the sudden infant death syndrome (cot death) is attributable to maternal smoking (equivalent to one death per day in England and Wales).

8. Infants of parents who smoke are twice as likely to suffer from serious respiratory infection.

9. Symptoms of asthma are twice as common in the children of smokers.

10. One-third of cases of 'glue ear', the commonest cause of deafness in children, is attributable to parental smoking.

11. Children of parents who smoke more than 10 cigarettes per day are shorter than children of non-smokers.

12. Passive smoking in childhoods is an important cause of school absenteeism accounting for one in seven days lost.

13. Parental smoking is responsible for at least 17,000 admissions to hospital each year of children under the age of five.

14. Passive smoking during childhood predisposes children to developing chronic obstructive airway disease and cancer as adults.

15. Elimination of parental smoking during early childhood would result in a substantial reduction in infant mortality.

Health problems of children who smoke

16. Nicotine is a drug of addiction. Many young smokers are addicted to nicotine and develop withdrawal symptoms on stopping.

17. Smoking is an important marker for other types of drug abuse, eg alcohol, cannabis, cocaine etc.

18. Young smokers have more respiratory infections with more time off work and school.

19. Teenage smokers have between two and six times more cough and sputum than nonsmokers.

20. Asthmatics who smoke have worse symptoms and lung function than non-smoking asthmatics.

21. The earlier children start smoking, the greater the risk of lung cancer in later life.

22. Smoking is a cardiac stimulant, which magnifies the effect of stress on the heart.

23. Smokers are less physically fit being both slower at sprints and endurance running. The performance in a half-marathon of a smoker of 20 cigarettes per day is that of a non-smoker 12 years older.

24. Smoking increases blood coagulability and adversely affects blood lipids.

25. Subarachnoid brain haemorrhage is six times more common in young smokers than non-smokers.

26. The earlier children start smoking, the younger they develop heart disease.

27. Smoking increases skin ageing and wrinkling.

28. Female smokers are two to three times more likely to be infertile. 
29. Smoking affects immunity and has been associated with an increased risk of HIV infection.

Prevalence of smoking in the young

30. Every day in Great Britain 450 children start smoking.

31. One-quarter of UK school leavers aged 15 years smoke regularly, ie at a time when it is illegal to sell them cigarettes. Little change has occurred in the last decade in the proportion of children who smoke. Present data suggest more girls than boys now smoke.

32. By the age of 11 years, one-third of children, and by 16 years, two-thirds of children have experimented with smoking.

33. Most adult smokers had started regular smoking before the age of 18 .

34. The high prevalence of regular smoking in young people and lack of any significant decline in the last decade is alarming.

\section{Factors that encourage children to smoke}

35. Smoking in the young is directly related to adult smoking. Important reductions in children's smoking will occur only when the role modelling of adults is considerably reduced.

36. Young regular smokers tend to be rebellious with poor self-image and indulge in risk-taking behaviour.

37. Parental smoking and attitudes are critically important influences on whether a child will smoke. Children are seven times less likely to smoke if they perceive strong disapproval from their parents.

38. In older children, the smoking habits of friends are important. Going against the group norm is difficult and refusal skills have to be learnt.

39. Non-smoking teachers and strict school No Smoking policies reduce cigarette consumption both in and out of school and in later life.

40. There are one-quarter of a million retail outlets selling tobacco in the UK of which half break the law on sales to children.

41. Regular price increases through taxation reduce tobacco consumption whilst government tax revenue actually increases.

42. The tobacco industry spends at least $£ 72$ million per year in the UK advertising and promoting cigarettes. Tobacco advertising perpetuates the myth that tobacco has significant positive qualities of success, glamour, speed and adult behaviour.

43. A tobacco price increase results in a greater reduction in consumption in young people than in adults. In terms of average disposable income, the price of a pack of cigarettes has halved in the last 30 years.

\section{Measures to reduce smoking in the young}

44. Children are considerably influenced by tobacco advertising and promotion, particularly girls. They need to be taught the skills to resist the marketing pressures to smoke.

45. There is an urgent need for immediate action to prevent an epidemic of smoking related disease in women occurring as a result of girls starting to smoke during school years.

46. A range of intervention strategies are available which if developed and implemented comprehensively would have a major effect in reducing children's smoking to undetectable levels.

47. These strategies should comprise developing personal skills in young people, creating supportive environments, strengthening community action, reorientating health services and building healthy public policy.

48. A ban on tobacco advertising and sponsorship as part of a comprehensive Tobacco Act would have a significant impact on the uptake of tobacco by young people in the UK.

49. There is an urgent need to develop coherent UK government and European Community strategies and policies on tobacco control if the public's health is to be substantially improved.

\section{Recommendations}

The whole of society carries a responsibility for the health of its children. As well as every individual setting an example to children by not smoking, the following groups have particular responsibilities and opportunities in respect of smoking to act in the interest of children's health.

\section{PARENTS should:}

- Stop smoking before and during pregnancy because this may harm their baby

- Seek advice, counselling and support to stop smoking in pregnancy and afterwards

- Refrain from smoking after pregnancy because smoking may damage their children's health and make it more likely that their children will smoke

- Give a firm message of disapproval of smoking to their children

- Support non-smoking education programmes in school and in the community

- Encourage schools, education authorities, governing bodies, health authorities and councils to face up to their responsibility to safeguard children's health

- Report breaches in the tobacco control measures for children, eg illegal sales and advertising.

\section{SCHOOL AND EDUCATION AUTHORITIES should:}

- Use innovative teaching methods to help young people develop the skills to resist peer and social pressures to smoke both in primary and secondary school 
- Involve the family and parents in nonsmoking education to reinforce classroom teaching

- Provide relevant information on short- and long-term effects of smoking on fitness, health, personal expenditure, appearance, environment, the economy and society as a whole

- Offer help to teachers to stop smoking

- Improve training of teachers and youth workers in health education

- Implement a total No Smoking policy in all schools, colleges and youth clubs

- Encourage the participation of children and young people in smoke-free programmes at school and in the community.

\section{THE MEDIA should:}

- Recognise and accept their responsibility towards safeguarding the health of children

- Understand that promotion of tobacco and role models who smoke increase uptake in children

- Refuse to accept overt or covert tobacco advertising and sponsorship

- Take action which encourages children not to smoke and avoid inadvertent editorial promotion of smoking

- Support smoking education programmes and give high status to non-smokers and ex-smokers.

\section{THE NATIONAL HEALTH SERVICE} should:

- Accept responsibility for local, district and regional leadership, co-ordinate effective smoking control programmes, and set up accountability mechanisms.

- Monitor and publish levels of smoking amongst young people at district level on a regular basis and encourage schools to do the same

- Monitor prevalence of smoking in pregnancy

- Ensure that smoking prevention and cessation is an important part of the work of all health care professionals in both hospital and community settings, and monitor their performance. Give special attention to children, pregnant women and parents

- Ensure all health premises are designated non-smoking and that health professionals set a good example by not smoking

- Encourage health workers who smoke to give up and provide smoking cessation opportunities for them

- Strengthen their public advocacy role for a smoke-free society, for example through the National Association of Health Authorities and Trusts, and through reports of Directors of public health medicine reports.

\section{LOCAL GOVERNMENT should:}

- Agree a No-Smoking policy for the council and ban smoking at council meetings

- Use all its powers to prevent tobacco advertising and promotion in the community

- Encourage Trading Standards Officers (a) to enforce legislation on sales of cigarettes to children and actively prosecute offenders, and (b) to monitor and take action on breaches of advertising controls

- Enable environmental health officers to encourage non-smoking policies in public places, work sites etc.

- Ban all smoking in leisure and sports centres and other public places owned by the council, especially where young people congregate

- Implement effective smoking control policies for their own employees and offer them help with smoking cessation.

\section{TOBACCO RETAILERS AND} RETAIL ORGANISATIONS should:

- Ensure that they do not endanger the health of children by selling or by permitting the sale of cigarettes to them

- Prominently display notices indicating that the sale of cigarettes to underage children is prohibited.

\section{HEALTH PROMOTION AGENCIES} should:

- Ensure that accessible and relevant information on all aspects of smoking is available to children, parents, schools, education authorities, health authorities etc.

- Mount and evaluate community-based initiatives for young people and adults, eg Smokebusters, Quite-and-Win Contests

- Encourage citizen action in relation to smoking in public places, work sites etc to create a climate of opinion which promotes non-smoking as the norm

- Mobilise public opinion to influence local and national decision-makers

- Use the media on a planned and opportunistic basis to promote a smoke-free society

- Recognise their responsibility to the health of young people when planning and setting priorities.

- Continue to invest in research an development studies and experimental and demonstration projects.

\section{CENTRAL GOVERNMENT should:}

- Legislate to ban all forms of direct and indirect tobacco promotion and advertising including arts and sports sponsorship

- Maintain a strong price disincentive on cigarettes for young people by regularly increasing the real price of tobacco products through taxation

- Introduce a special tax on tobacco to finance smoking prevention and related health research

- Raise the legal age for buying tobacco to 18 years

- Diligently enforce and monitor legislation

$$
\begin{aligned}
& = \\
& = \\
&
\end{aligned}
$$


on sales to children and, if current measures are ineffective, consider introducing licensing arrangements for the sale of tobacco

- Improve health warnings on tobacco products so they are tougher, more prominent and oriented to young people

- Introduce plain packaging requirements for cigarette manufacturers

- End all national and European aid for production, manufacture and promotion of tobacco products and encourage diversification out of tobacco

- Enact legislation to ban smoking within 5 years in public places and especially in all schools, sports and leisure facilities and NHS premises

- Enact legislation for the right to work in a smoke-free environment

- Establish a Ministerial Action Group to ensure that relevant Departments develop and implement effective tobacco control policies.
9. DOCTORS should:

- Set an example by not smoking in public, and seek help to give up

- Demonstrate concern for effective smoking control policies in their own workplaces

- Offer sympathetic and effective smoking cessation advice to their parents and encourage non-smokers including children to remain smoke-free

- Challenge publicly poor role models in public life and irresponsible organisations

- Write to Members of Parliament and to local counsellors to inform them of smoking and health issues

- Support and encourage medical and other health bodies who are working at a national level to combat smoking

- Initiate a 'Doctors' Smoke-Free Action Group' to ensure progress is made locally. 